\title{
FUELING THE FUTURE: ENERGY EDUCATION FOR WESTERN NEW YORK
}

ABSTRACT

As a non-profit cultural institution the Buffalo Museum of Science (BMS) accepts cuany chistions

(n) On

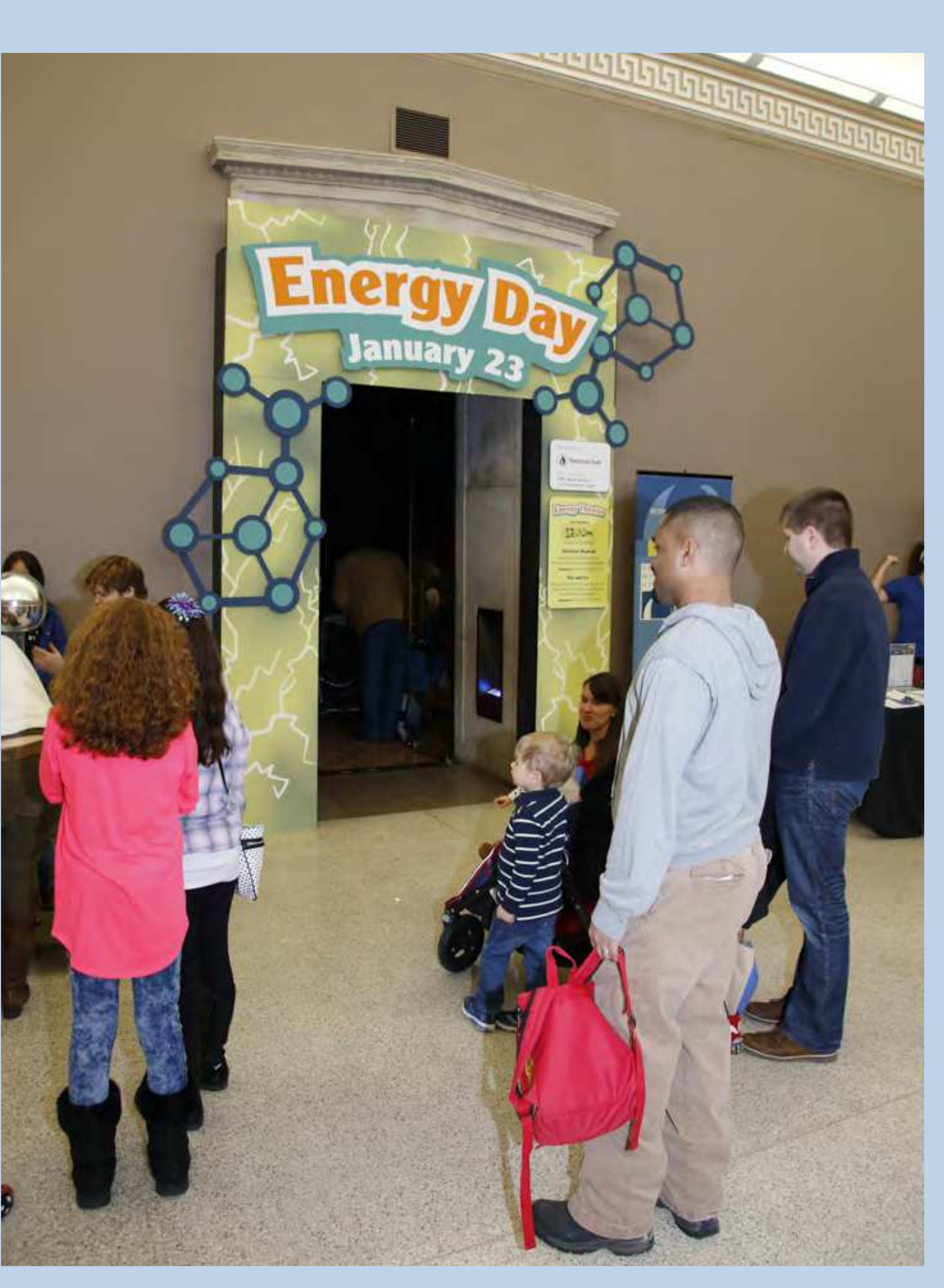
the BMS's generous partners is a gas and transports natural gas in the Western New York and Northwestern Pennsylvania regions. The goal of the partnership gions. between the BMS and this distribution corporation is to educate students [children of our shared customers and client families] to the benefits of using natural gas and the potential risks associated with this resource. In the past, areas of focus included

practical in-home application of
using natural gas and more importantly, recognition of any mmediate dangers that come with a gas leak.

BMS educators initially sought to achieve this objective through a eries of fun festivals, theme days, and classroom outreaches at 10 the servicing region of the funding corporation. Activities includin scratch-and-sniff cards demonstrating that naturally occurring gas is colorless and odorless, and that the rotten egg, or sulfur, scent we ense is the result of an additive by the gas company to increase safety. These programs were successful introductions to states of matter and effectively communicated the gas corporation's key concepts around gas safety.

With renewed funding for the upcoming academic year, the BMS and its informal educators have the opportunity to evolve their techniques, offering deeper, higher quality experiences, and content focusing on the geology of the rock unit where natural gas is found and the science and technology needed to extract this non-renewable resource. BMS educators remain unbiased in content delivery in order to correctly and effectively communicate the science and technology supporting this field. The museum is grateful for the opportunities its funding partner is providing to associated with climate and $\mathrm{k}$-12 setin todays ever chonging world and society.

\section{INTRODUCTION}

Informal education is defined as the wise, respectful, and spontaneous process of cultivating learning. It works through conversation, and the exploration and enlargement of experience (Jeff sans Smith, 2005). The social pedagogy associated with the conversations around informal education lend themselves to a enhancing the sense of community (Sennett, 2012).

IMPLICATIONS

In the past, grant funded education included outreach programs, in the form of fun festivals, public theme day weekends, and theme days for schools, solely focusing on the mass education of phases of matter, natural gas recognition, and alternative energies, primarily in a lecture style setting. While thousands were served, the impact of the programming generally remained surficial. Now,

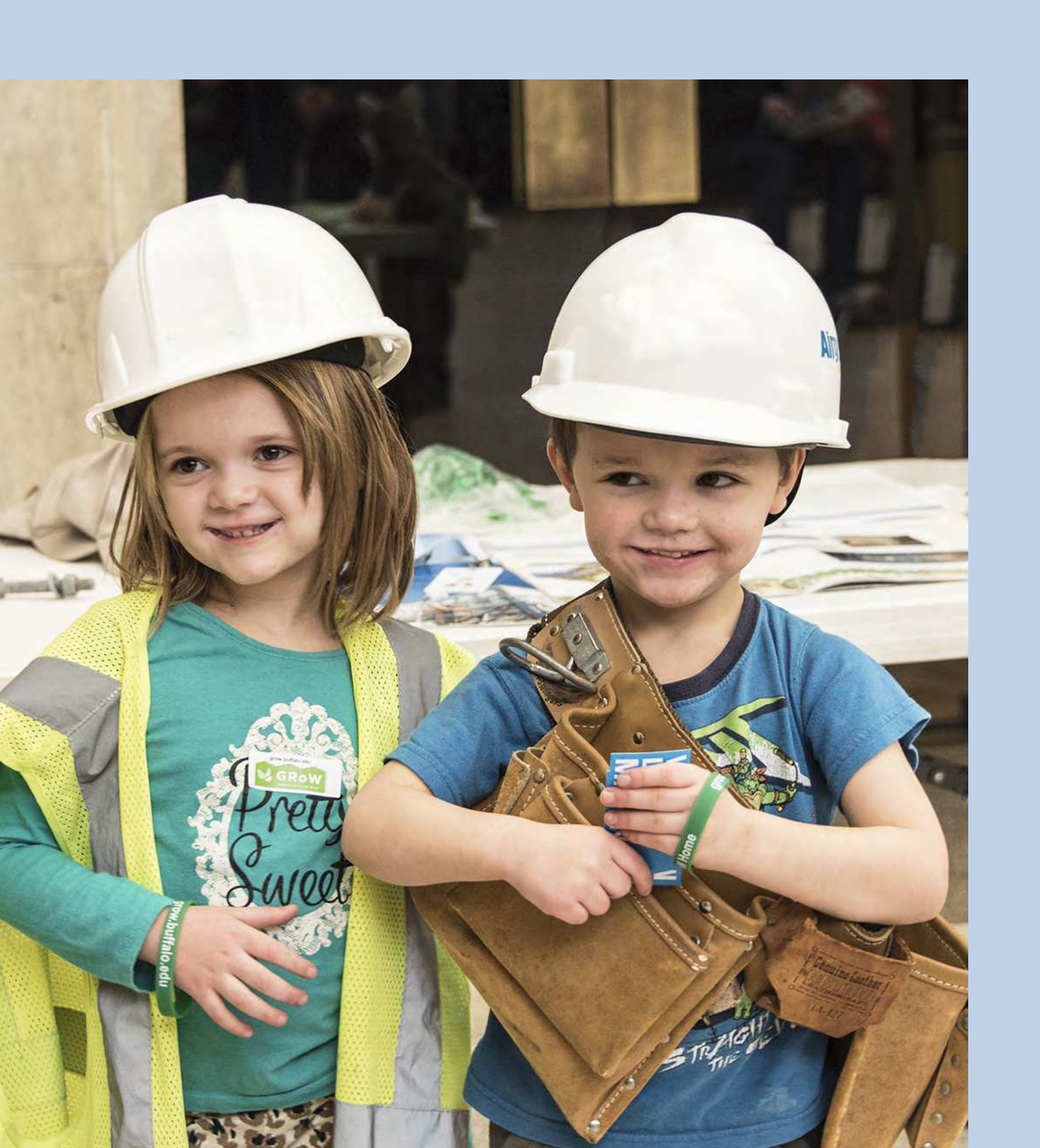
W have decided to rework the curriculum to provide more impactful programming more coly connected to classroom outcomes. The new creative choices of the BMS's educators will include the services offered in years past, but will also integrate facilitated workshops focused on geology laboratory assignments and the drilling techniques and technologies associated with the natural
作

Buffalo Museum of Science

1020 Humboldt Parkway
Buffalo, NY 14211

(716) 896-5200 | sciencebuff.org

gas industry. These facilitated workshops will lend themselves to a more focused and infuentia participating thus enhancing participant involvement and retention. Funds for transportation will also be included in the grant this year, making it possible to reach students who may have been inaccessible before. The new suite of programming designed by the informal educators of the BMS will lend itself to a higher quality of material and content presented, and thus be more enriching, although the total served will slightly decrease.

ADDITIONAL INFORMATION

The partnership between the BMS and the local gas distribution corporation is valuable, for geographical and scientific reasons. The Marcellus shale, and what it holds for gas distribution accessibility and proximity. Thanks to the shift in focus of the fue industry, it provides a useful opportunity to talk about the ever improving scientific and technological advancements that exist

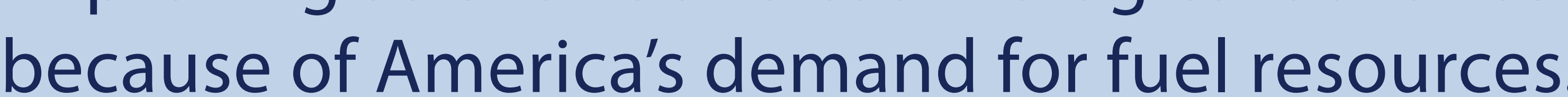

CONCLUSION

While there are no quantitative results, other than the number of total served during the lifespan of this grant, there are conclusive qualitative results. Students participants are acquiring new knowledge and the funding corporation's community engagement objectives are being achieved. The BMS is proud to serve as a catalyst with the public on such issues. The BMS believes these partnerships build the institution's foundation as a trusted resource for the communities of Western New York. To continue generating the greatest learning impact and outcomes it will be critical for the BMS to secure additional participant feedback.

HISTORY OF THE BUFFALO MUSEUM OF SCIENCE The Buffalo Society of Natural Sciences was founded in 1861 as a result of the growing cultural, scientific, and collecting interest of Science opened its doors to the public in 1929. Today, the museum welcomes nearly 200,000 guests annually, has, membership base of over 6500 and conducts innovative informal learning programs for all ages.

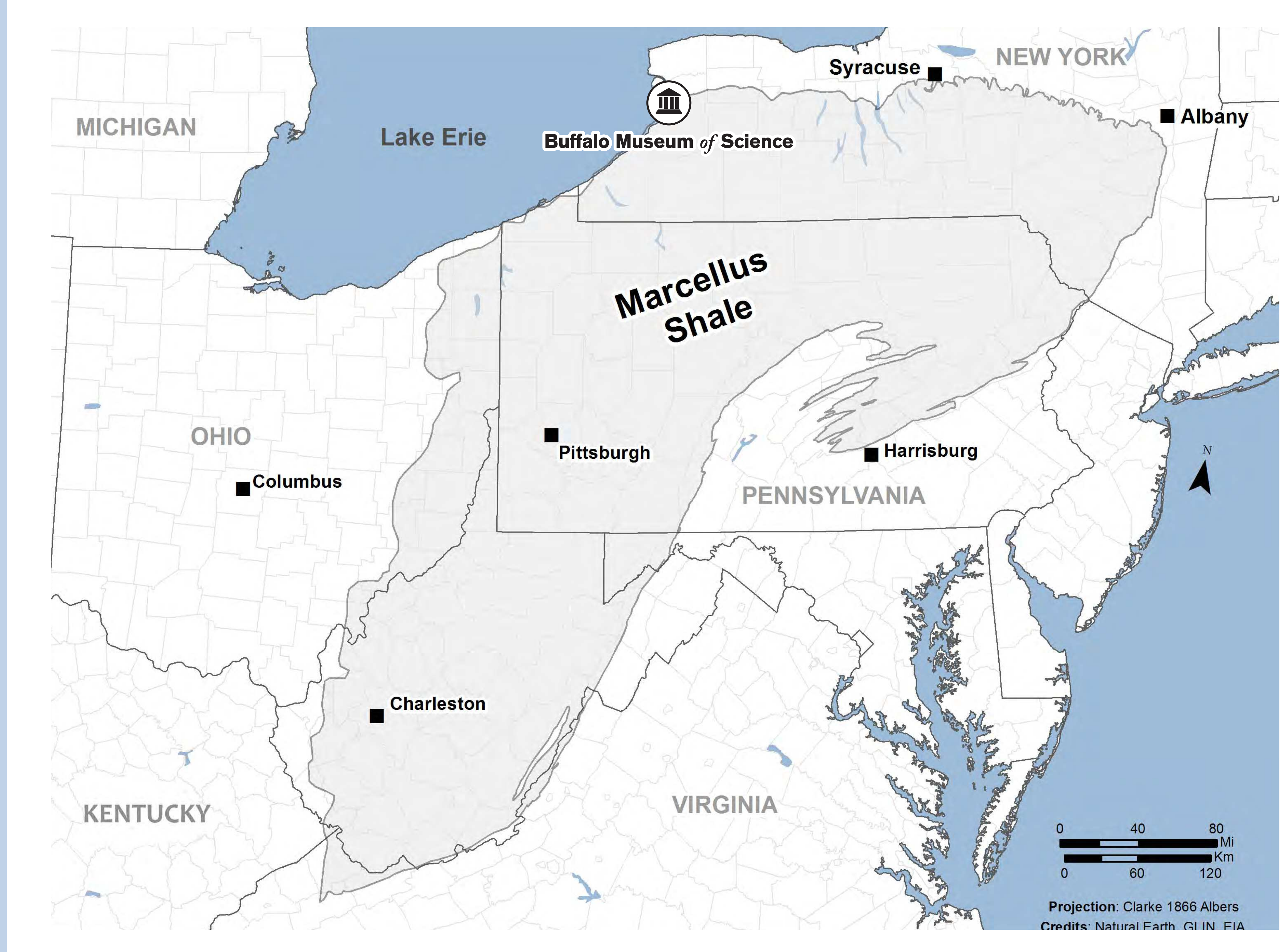

REFERENCES

Buffalo Museum of Science: http://www.sciencebuff.org/site/

Jeffs, T. and Smith, M. K. (1997, 2005, 2011).' What is informal education?' the encyclopedia of informal education.

. Sennett, Richard. (2012). 'Tog
Cooperation' University Press 